Neurology"

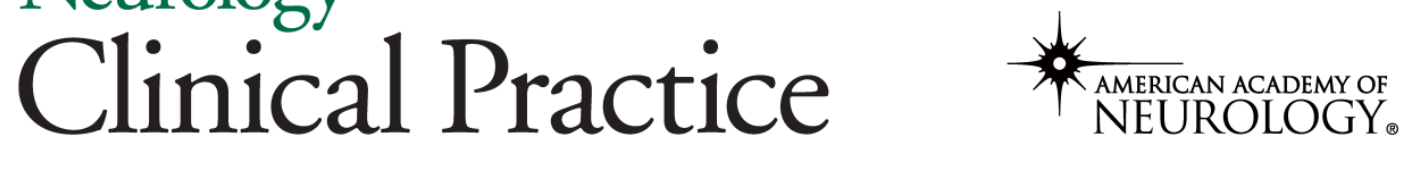

A peer-reviewed clinical neurology journal for the practicing neurologist An Official Journal of the American Academy of Neurology

Neurology: Clinical Practice Publish Ahead of Print

DOI: 10.1212/CPJ.0000000000001066

\title{
Epilepsy Treatment Complacency in Patients, Caregivers, and Healthcare Professionals
}

Patricia E. Penovich, MD ${ }^{1}$; John M. Stern, $\mathrm{MD}^{2} *$; Danielle A. Becker, $\mathrm{MD}^{3}$; Lucretia Long, APRN-CNP ${ }^{4}$; Nancy Santilli, PNP, $\mathrm{MN}^{5}$; Lynanne McGuire, $\mathrm{PhD}^{6}$; Eugenia Y. Peck, $\mathrm{PhD}^{7}$

This is an open access article distributed under the terms of the Creative Commons AttributionNonCommercial-NoDerivatives License 4.0 (CC BY-NC-ND), which permits downloading and sharing the work provided it is properly cited. The work cannot be changed in any way or used commercially without permission from the journal.

Neurology ${ }^{\circledR}$ Clinical Practice Published Ahead of Print articles have been peer reviewed and accepted for publication. This manuscript will be published in its final form after copyediting, page composition, and review of proofs. Errors that could affect the content may be corrected during these processes. 
${ }^{1}$ Minnesota Epilepsy Group, Saint Paul, MN; ${ }^{2}$ Department of Neurology, University of California at Los Angeles, Los Angeles, CA, ${ }^{3}$ Penn Epilepsy Center, Hospital of the University of Pennsylvania, Philadelphia, $P A^{a}$; Department of Neurology, The Ohio State University Medical Center, Columbus, OH; ${ }^{5}$ Human Care Systems, Inc., San Francisco, CA; ${ }^{6}$ MedVal Scientific Information Services, Princeton, NJ; ${ }^{7}$ Health Division, Kantar Health, New York, NY

*These authors contributed equally to the manuscript and are co-first authors.

${ }^{a}$ Affiliation at the time the work was done.

Data analysis was conducted by Eugenia Y. Peck, PhD, Kantar Health, New York, NY.

\section{Correspondence:}

Patricia E. Penovich, MD

Email: ppenovich@mnepilepsy.net

\section{Submitting to: Neurology Clinical Practice}

Counts: Title: 84 characters; Text (Introduction through Discussion): 3168 words; Abstract: 250 words; Introduction, 154 words; References: 22; Figures 5, Tables 0.

Search terms: All Epilepsy/Seizures [60]; Antiepileptic drugs [61]; Epilepsy surgery [66]; treatment decisions, survey.

\section{Study funding}

This study was funded by SK Life Science, Inc.

\section{Disclosure}


P. E. Penovich is an advisor for Engage, LIVIS, Neurelis, and SK Life Science, Inc.; and has been a speaker for GW Pharmaceuticals, Neurelis, SK Life Science, Inc., and UCB Pharma.

J. M. Stern is a consultant for Eisai, Greenwich, LivaNova, SK Life Science, Inc., Sunovion, and UCB Pharma.

D. A. Becker is an advisor for Neurelis, SK Life Science, Inc., and Supernus; and has been a speaker for NeuroPace, Supernus, and SK Life Science, Inc.

L. Long is an advisor for Eisai, Neurelis, SK Life Science, Inc., Supernus; and has been a speaker for LivaNova.

N. Santilli is a consultant/advisor for Neurelis and SK Life Science, Inc.

L. McGuire is an employee of MedVal Scientific Information Services, which was contracted by SK Life Science, Inc for medical writing services.

E. Y. Peck is an employee of Kantar Health, which provided consulting services to SK Life Science, Inc., for this study.

\section{Previous presentation}

Penovich PE, et al. Treatment complacency among patients living with epilepsy, caregivers, and healthcare professionals. Neurology 2020;94(15 suppl):S59-007. Abstract.

Stern JM, et al. Perspectives on epilepsy-related fears among adult patients living with epilepsy, caregivers, and healthcare professionals. Neurology 2020;94(15 suppl):P15-009. Abstract.

Patricia E.Penovich, ppenovich@mnepilepsy.net

John M. Stern, jstern@ucla.edu

Danielle A. Becker, dbecker8@gmail.com

Lucretia Long, lucretia.long@osumc.edu 
Nancy Santilli, nancysantilli01@gmail.com

Lynanne McGuire, lynanne.mcguire@ medvalsci.com

Eugenia Y. Peck, eugenia.peck@kantarhealth.com 


\section{ABSTRACT}

Objective: To explore the perspectives of adult patients with epilepsy, caregivers, and healthcare professionals (HCPs) on treatment for seizures and treatment decisions, we developed and administered the STEP Survey (Seize the Truth of Epilepsy Perceptions).

Methods: Participants were recruited from online panel M3 and by Rare Patient Voice and completed the self-administered online STEP Survey. Analysis of variance and chi-square tests were used for group comparisons.

Results: The STEP Survey was completed by 400 adult patients, 201 caregivers, and 258 HCPs. Patients estimated reporting $45 \%$ of their seizures to their HCP, whereas caregivers estimated $83 \%$ and HCPs estimated $73 \%$ were reported. The most common reason for not reporting seizures was the seizures were "not serious enough to mention" (patients 57\%; caregivers 66\%). A minority of patients (25\%) and caregivers (30\%) were very or extremely likely to ask their HCP about changing antiseizure medication (ASM) in the next 12 months. The HCP was most frequently selected by patients, caregivers, and HCPs as the person who initiates discussion of changing ASMs (patients 73\%/caregivers 66\%/HCPs 75\%) and increasing ASM dosage (patients $77 \% /$ caregivers $68 \% / \mathrm{HCPs} 81 \%$ ). A majority of patients (65\%) and caregivers (68\%) somewhat or strongly agreed they do not change ASMs due to fear of getting worse. HCPs perceive this fear less often, stating $50 \%$ of their patients feel afraid when a second ASM was added.

Conclusions: Improved reporting of all seizures, discussion of treatment changes, and the impact of fear on treatment decisions provide opportunities to reduce complacency and optimize patient outcomes. 


\section{TAKE-HOME POINTS}

- The STEP Survey (Seize the Truth of Epilepsy Perceptions) revealed complacency of patients and caregivers toward making changes in treatment

- Patients report fewer of their seizures than either caregivers or HCPs believe they report

- A minority of patients and caregivers initiate discussion of treatment changes with their HCP

- A majority of patients and caregivers do not change treatment due to fear of their seizures getting worse

- HCPs have an opportunity to reduce the impact of fear on treatment decisions and improve patient QOL

\section{INTRODUCTION}

Seizure freedom with minimal adverse effects is the ideal goal of epilepsy treatment, ${ }^{1-3}$ yet approximately $40 \%$ of patients do not achieve 1 -year seizure freedom despite treatment with two antiseizure medications (ASMs) and $56 \%$ of patients treated with ASMs do not achieve seizure

freedom in the preceding year. ${ }^{4,5}$ The physical, social, and emotional consequences of uncontrolled seizures compared with seizure freedom are substantial and may include cognitive decline, reduced quality of life, higher risk of mood disorders, greater stigma, and increased risk of premature death. ${ }^{6-9}$

The STEP Survey (Seize the Truth of Epilepsy Perceptions) was developed to examine patient, caregiver, and healthcare professional $(\mathrm{HCP})$ perspectives on seizures, treatment experiences, treatment satisfaction, pathways to treatment changes, and the effect of epilepsy and its treatment on the day-to-day lives and emotions of patients and caregivers. In this report we examine treatment complacency and factors that may underlie treatment decisions in adults living with epilepsy, caregivers, and HCPs. 


\section{METHODS}

\section{Study design}

The self-administered, online STEP Survey was developed by SK Life Science, Inc., and this cross-sectional study was conducted by Kantar Health in 2019. The survey was written at a 7th grade reading level and included input from patients, HCPs, and the Epilepsy Foundation. The survey incorporated several quality checks to verify all logic, ranges, termination points, and open-ended questions, and required approximately 40 minutes (patients and caregivers) to 45 minutes (HCPs) to complete. The STEP Survey questions addressed (1) epilepsy disease experience; (2) seizure freedom, seizure control, and seizure reduction; (3) treatment experience and goals; (4) life challenges in managing epilepsy; (5) the HCP/patient experience; (6) communication among patients, caregivers, and HCPs; (7) types and sources of epilepsy information; and (8) support networks.

\section{Participants}

Adult patients with epilepsy, caregivers of patients with epilepsy, and HCPs who treat patients with epilepsy were recruited from online panel M3 and by Rare Patient Voice. Online panel M3 is an opt-in panel, meaning that people who joined the panel decided to participate regularly in surveys. An invitation to participate in the study was sent to panel members by email with a link to the survey. Patients with epilepsy also were recruited by Rare Patient Voice, an organization that specializes in patient recruitment services for the pharmaceutical industry. Rare Patient Voice uses an opt-in database and recruits patients through connections with support groups. An invitational email with a link to the survey was sent to identified patients. 
Eligible participants lived in the United States and understood English, the language used in the survey. Eligible patients were $\geq 18$ years old, diagnosed with epilepsy (generalized, focal, or unknown), and currently on one or more ASMs. They were currently under the care of a general neurologist, epileptologist, or nurse practitioner (NP)/physician assistant (PA) at a neurology practice, or a primary care physician. Eligible caregivers were $\geq 18$ years old and were providing care for a person of any age with epilepsy who met the study patient eligibility criteria. Eligible caregiving (only one type needed) included reminding the patient to take medicine, attending epilepsy doctor appointments, knowing what to do during a seizure, talking to epilepsy doctors, picking up epilepsy medications, cooking or cleaning for the patient, driving the patient, helping the patient keep to a schedule, and keeping the environment safe from possible seizures.

Eligible HCPs included general neurologists (hereafter neurologists), epileptologists, and NPs/PAs. Eligibility criteria for neurologists and epileptologists included in practice 2-30 years and either board certification or eligibility in neurology. Neurologists and epileptologists had to spend $\geq 70 \%$ of their professional time treating patients, $>50 \%$ of whom were adults, including treating $\geq 20$ adult patients with epilepsy in a typical month and treating $\geq 15$ adult patients with focal seizures in a typical month. Eligible NPs/PAs worked in an office with a neurologist or epileptologist, were in practice $2-30$ years, and spent $\geq 70 \%$ of their professional time treating patients. NPs/PAs had to work in practices with $>50 \%$ adult patients, $\geq 20$ adult patients with epilepsy treated in a typical month, and $\geq 5$ adult patients with focal seizures treated in a typical month.

The patient, caregiver, and HCP groups were independent of one another and were not a matched set. Participants received compensation; \$25 for M3 panel participants, \$70 for patients from 
Rare Patient Voice, and \$72 for HCPs, based on assessed fair market value for HCP survey response time.

\section{Standard protocol approvals, registrations, and patient consents}

The STEP Survey was deemed IRB exempt (Sterling IRB, Atlanta, GA). All potential respondents provided online informed consent before screening for eligibility and beginning the survey.

\section{Data analysis}

Consistency checks, quality control, and validation processes confirmed data quality. A total of 850 participants was planned, including 400 patients, 200 neurologists (approximately 75 epileptologists), 50 NP/PAs, and 200 caregivers. Means, standard deviations, and analysis of variance were used with continuous variables. Percentages, frequencies, and chi-square tests were used with categorical variables. The number of assessed respondents were reported when missing data occurred.

\section{Data availability}

The data are available by request from the authors or from SK Life Science, Inc.

\section{RESULTS}

Four hundred adult patients with epilepsy, 201 caregivers, and 258 HCPs, including 112 neurologists, 96 epileptologists, and 50 NPs/PAs, completed the online STEP Survey. The mean age of patients was 40.2 years, of caregivers was 40.5 years, and of HCPs was 44.9 years. Patients had a mean epilepsy duration of 16 years and caregivers had a mean caregiving duration of 10.7 years. Among patients and caregivers, $76 \%$ were women, and $67 \%$ of the HCPs were 
men. Patient-reported epilepsy type included generalized (41\%), focal (41\%), unknown origin (16\%), do not remember (5\%), and other (1.5\%). Patients primarily received treatment from neurologists (78\%), epileptologists (16\%), NPs/PAs (4\%), and primary care physicians (3\%). At least one seizure with impaired awareness in the past year was reported by $61 \%$ of patients. Half (52\%) of patients reported $1-9$ seizures in the past year, $15 \%$ reported $10-20$ seizures, $16 \%$ reported $>20$ seizures, and $17 \%$ reported zero seizures in the past year. More than half of patients $(58 \%)$ were on their third or more ASM regimen, $25 \%$ were on their second ASM regimen, and $17 \%$ were on their first ASM.

Caregivers were a partner (23\%), a parent (25\%), an adult child (13\%), another type of family member $(27 \%)$, or a friend $(11 \%)$ of the person with epilepsy. They lived in the same home as the person with epilepsy (66\%), in the same neighborhood but not the same home (16\%), in the same town but not the same neighborhood (5\%), in a nearby town (10\%), and in another town at least an hour away (3\%).

Among neurologists, epileptologists, and NPs/PAs, the mean years in practice were 14.7, 11.8, and 8.7 years and the average percentage of patients with focal seizures was $67 \%, 66 \%$, and $55 \%$, respectively. Patients treated by the neurologists, epileptologists, and NPs/PAs were on their first $(49 \%, 40 \%, 45 \%$, respectively), second $(31 \%, 32 \%, 33 \%$, respectively), or third or more $(18 \%, 23 \%, 19 \%$, respectively) ASM, or were not on an ASM (2\%, 5\%, 3\%, respectively).

\section{Report of seizures}

Patients, caregivers, and HCPs differed in their estimates of the percentage of seizures patients report to their HCP. Patients estimated reporting $45 \%$ of their seizures, whereas caregivers estimated $83 \%$. HCPs estimated that patients report $73 \%$ of their seizures, and half of the HCPs 
somewhat (36\%) or strongly (17\%) agreed that their patients report every seizure. The most common reason given by patients and caregivers for why seizures were not reported is that the seizures were "not serious enough" to mention (patients $57 \%$; caregivers $66 \%$ ), followed by forgetting to mention the seizures (patients 33\%; caregivers 43\%) (Figure 1).

\section{Treatment discussions}

A minority of patients (25\%) and caregivers (30\%) reported that they were very/extremely likely to ask their HCP about changing treatment in the next 12 months, including adding another ASM (patients 21\%; caregivers 29\%), increasing ASM dosage (patients 19\%; caregivers 29\%), or decreasing ASM dosage (patients 16\%; caregivers 23\%) (Figure 2).

Patients, caregivers, and HCPs were asked to select who initiates discussions about changing ASMs and about increasing ASM dosage. There was agreement that the HCP is the person who initiates treatment discussions. A high percentage of patients (73\%), caregivers (66\%), and HCPs (75\%; neurologists and epileptologists $>$ NP/PAs, $p<0.05$ ) selected "HCP" as the person who initiates discussion about changing ASMs. Similarly, a high percentage of patients (77\%), caregivers (68\%; caregivers < patients and HCPs, $p<0.05)$, and HCPs $(81 \%)$ selected "HCP" for initiating discussion about increasing ASM dosage. There was divergence in perspectives on whether the "Patient" and "Caregiver" initiate ASM discussions. More patients (39\%) selected "Patient" as initiating discussion about changing ASMs compared with caregivers (28\%) and HCPs $(9 \% ; p<0.05)$. Fewer HCPs $(1 \%)$ selected "Patient" as initiating discussion about increasing ASM dosage compared with patients (27\%) and caregivers $(24 \%, p<0.05)$. More caregivers (35\%) selected "Caregiver" as initiating discussion about changing ASMs compared with patients $(11 \%)$ and HCPs $(2 \%, p<0.05)$, and more patients than HCPs selected "Caregiver" 
$(p<0.05)$. More caregivers $(29 \%)$ also selected "Caregiver" as initiating discussion about increasing ASM dosage compared with patients (9\%) and HCPs $(2 \%, p<0.05)$.

Half of patients $(54 \%)$ and $42 \%$ of caregivers $(p<0.05)$ reported no discussion of surgical treatment for epilepsy with their HCP (Figure 3). Among those who discussed surgery, vagus nerve stimulation (patients 34\%; caregivers 40\%) and responsive neurostimulation (patients $17 \%$; caregivers $24 \%, p<0.05$ vs patients) were most frequently discussed. The survey was conducted prior to the US FDA's approval of deep brain stimulation for epilepsy. HCPs most often reported discussion of vagus nerve stimulation (21\%), cortical resection (11\%), and responsive neurostimulation (10\%) (Figure 3).

\section{Epilepsy specialist referral}

Among patients with more than 1 seizure in the preceding 12 months, $18 \%$ of patients and $17 \%$ of caregivers reported referral to an epilepsy center, and $21 \%$ of patients and $24 \%$ of caregivers reported referral to another epilepsy specialist. Of the patients with $\geq 13$ seizures per year, $27 \%$ reported referral to an epilepsy center. HCPs referred $14 \%$ of their patients to another epilepsy specialist and $16 \%$ to an epilepsy center. Among the HCPs who referred $(n=219)$, the most common reasons included the patient was a surgery candidate $(82 \%)$, the patient was having significant breakthrough seizures on a third or more ASM regimen (73\%;

neurologists>epileptologists and NPs/PAs>neurologists and epileptologists; $p<0.05)$, and the patient requested the referral $(49 \%)$.

Patients, caregivers, and HCPs were asked how important it is that a patient treatment map be implemented that tells patients and caregivers to see an epileptologist or specialist as soon as they have symptoms and not wait for a longer time. The majority of patients $(61 \%)$, caregivers 
(68\%), and HCPs (61\%) agreed that such a treatment map is very/extremely important (Figure 4).

\section{Fear of seizures}

Epilepsy-related fear was pervasive, as $39 \%$ of patients reported "epilepsy makes me always feel afraid." Most patients (83\%) and caregivers (94\%) reported they somewhat/strongly agree they live in fear of another seizure, no matter how long it has been since the most recent seizure. Among HCPs, 78\% reported somewhat/strongly agree that their patients will always be afraid that another seizure will come. A greater percentage of caregivers reported fear of another seizure as compared to patients and HCPs $(p<0.05)$.

Patients and caregivers reported being very/extremely afraid of having a seizure in diverse situations, with half or more of patients indicating while alone (50\%), in a public place (53\%), and while driving (57\%) (Figure 5). More than half of caregivers indicated being very/extremely afraid of their loved one having a seizure while in a public place (52\%), asleep (56\%), showering (57\%), driving (61\%), and while alone (77\%). Almost half of patients (47\%) and HCPs (48\%) indicated that the patient's worrying about having a seizure in a public place is very/extremely disruptive to their quality of life (QOL). Among caregivers, $48 \%$ reported that worrying about their loved one having a seizure when they are not there is very/extremely disruptive to their QOL.

\section{Fear of changing treatment}

When presented with the statement, "I do not want to change my/my loved one's medications because I am afraid I/my loved one will get worse," $65 \%$ of patients and $68 \%$ of caregivers somewhat/strongly agreed. Patients $(11 \%)$ and caregivers $(5 \%)$ who reported being not at all/not 
very satisfied with the patient's HCP were asked what prevents the patient from switching HCPs. Half of these caregivers and $26 \%$ of these patients selected that I/my loved one is "afraid to lose all I/my loved one has worked for."

When asked how likely they were to ask their HCP about changing treatments in the next 12 months, $52 \%$ of patients and $37 \%$ of caregivers reported not at all/not very likely. Among this group of patients and caregivers $(n=281), 55 \%$ of patients and $59 \%$ of caregivers reported they do not want to risk the progress they have made on medication by changing, and $41 \%$ of patients and $39 \%$ of caregivers reported they do not want to risk having side effects on a new medication. When asked how they think their adult patients feel on each ASM treatment (ie, select 5 of the 13 descriptors: trapped, hopeless, angry, depressed, supported, isolated, afraid, vulnerable, accepting, optimistic, relieved, overwhelmed, other), 29\% of HCPs selected "afraid" for the first ASM, which increased to half selecting "afraid" for the second (50\%) and third (51\%) ASMs.

Among patients without a history of epilepsy surgery $(n=102)$ and their caregivers $(n=63), 42 \%$ of patients and $56 \%$ of caregivers selected "does not want to take the risk." A greater percentage of caregivers (56\%) vs patients (28\%) reported that I/my loved one is afraid of epilepsy-related surgery $(p<0.05)$.

\section{DISCUSSION}

Treatment complacency was common among patients, caregivers, and HCPs, despite uncontrolled seizures in many patients. STEP Survey responses point to several factors that may underlie treatment complacency. A key factor is that patients are reporting fewer than half of their seizures to their HCPs, whereas caregivers and HCPs estimated a higher percentage reported. This disconnect likely contributes to delays of discussions of treatment changes. A 
delay in HCP discussion initiation could have a meaningful effect on treatment complacency in that HCPs were selected as most likely to start treatment change discussions. To close the gap between seizures experienced and seizures reported to HCPs, the reasons patients provided for not reporting a seizure (ie, not serious enough, forgetting, lose driver's license, HCP did not ask) should be addressed. Improved reporting of all seizure occurrences and more frequent discussion of potential treatment changes, initiated by patients and caregivers as well as HCPs, may be needed to optimize treatment outcomes.

A second important factor for patients is fear that their seizures will worsen if they adjust their ASM regimen, and this may be an undisclosed reason for not reporting seizures. Fear of having another seizure pervades living with epilepsy for patients and caregivers and impacts treatment decisions. Patients and caregivers were very/extremely afraid of seizures occurring within diverse settings (eg, alone, public place, driving, showering, sleeping), and worrying about having a seizure in a public place (patients) or when alone (caregivers) was very/extremely disruptive to QOL for approximately half of the patients and caregivers. These findings are consistent with patient-reported fear related to reactions of friends, family and others, and fear of future episodes. ${ }^{10}$

Half of the patients were not at all/not very likely to ask their HCP about changing ASMs in the next year. Key fears that may drive this decision include fear of deterioration in seizure control, reported by half of these patients, and fear of potential adverse effects of a new ASM, reported by $41 \%$ of these patients. HCPs are aware of patients' fear with an increased number of ASMs tried, recognizing that half of their adult patients feel afraid for the second and third ASM regimens. Since ASMs are the predominant management approach for epilepsy, ${ }^{11,12}$ and all ASMs may be associated with adverse effects that can result in treatment discontinuation, 
nonadherence, or reduced quality of life, ${ }^{11,13-15}$ ongoing discussions about possible ASM changes and management of adverse effects are needed to allay patients' fears of changing treatment.

Fear of changing ASM treatment also was identified in the EPINEEDS study. ${ }^{16,17}$ An anonymous survey evaluated the priorities of patients with epilepsy and their physicians within secondary and tertiary epilepsy centers in Italy. Approximately half of the patients $(56.5 \%)$ had seizure remission for 1 year or longer. Despite overall satisfaction with disease management for most patients, there were differences in priorities among patients and physicians, as seen in our study. A greater percentage of patients than physicians considered limitation of daily life activities, discovery of the cause of seizures, use of the right drug, and minimization of long-term side effects to be high priorities. These differences remained when grouped by patient prognostic categories (ie, newly diagnosed, seizure remission, recurrent seizures, drug-resistant seizures). ${ }^{17}$ Both patients and physicians reported fear of short-term and long-term side effects for new ASMs. ${ }^{16,17}$

Implementation of a patient treatment map that tells patients to see an epileptologist or epilepsy specialist health care provider as soon as they have symptoms was very/extremely important to the majority of respondents. Such a treatment map may help to reduce treatment complacency by encouraging earlier referral to a/another specialist or an epilepsy center for further evaluation of diagnosis, advanced medication options, or possible surgical evaluation. Specialist or epilepsy center referrals were not common among the STEP Survey respondents, consistent with infrequent and long-delayed referrals to epilepsy centers in patients with medication-resistant epilepsy $^{18-21}$ despite the American Academy of Neurology Quality Measures standard of care of referral of patients with treatment-resistant epilepsy to an epilepsy center every 2 years. ${ }^{22}$ The discussion of epilepsy treatment options involving surgery was limited and patients and 
caregivers identified patient fear as a reason for not evaluating this treatment option. HCPinitiated discussion of potential fear of starting a new medication or epilepsy-related surgical intervention may allow patients with seizures suitable for these options to consider these treatment changes earlier.

A potential limitation in using the STEP Survey results to widely inform clinical practice is that the surveyed patients with epilepsy may be more treatment-resistant than the general epilepsy population, with a regimen of 3 or more ASMs reported by more than half of the patients. Also, the STEP Survey patients, caregivers, and HCPs were not a matched set, and responses may have been affected by differences among the sampled populations (eg, the patient respondents may be a more treatment-resistant population than the patients being treated by the HCP respondents).

In conclusion, evaluation of the perspectives of patients, caregivers, and HCPs confirmed that treatment complacency is common despite controlled seizures with many medication side effects or uncontrolled seizures. Potential strategies to mitigate treatment complacency and optimize treatment outcomes include improved reporting of all seizure occurrences and frequent discussion of and education about possible treatment changes. Although patients and caregivers experience pervasive fear and worry about seizures, this may not motivate patients with intolerable side-effects or uncontrolled seizures to seek treatment changes due to fear of worsening seizures or side effects. Knowledge of these fears provides an opportunity for HCPs to provide broader care, potentially reduce the impact of fear on treatment decisions, and ultimately improve quality of life. 


\section{Acknowledgments}

The authors thank Don Fallon, ELS, of MedVal Scientific Information Services, LLC (Princeton, NJ) for providing medical editing assistance (reviewed journal requirements, copyedited manuscript, prepared manuscript for submission), which was funded by SK Life Science, Inc. This manuscript was prepared according to the International Society for Medical Publication Professionals' "Good Publication Practice for Communicating Company-Sponsored Medical Research: GPP3."

\section{Appendix 1. Authors}

\begin{tabular}{|c|c|c|}
\hline Name & Location & Contribution \\
\hline Patricia E. Penovich, MD & $\begin{array}{l}\text { Minnesota Epilepsy Group, Saint } \\
\text { Paul, MN }\end{array}$ & $\begin{array}{l}\text { Interpreted the data; revised the } \\
\text { manuscript for intellectual content; } \\
\text { approved the final version for } \\
\text { submission. }\end{array}$ \\
\hline John M. Stern, MD & $\begin{array}{l}\text { University of California at Los } \\
\text { Angeles, Los Angeles, CA }\end{array}$ & $\begin{array}{l}\text { Interpreted the data; revised the } \\
\text { manuscript for intellectual content; } \\
\text { approved the final version for } \\
\text { submission. }\end{array}$ \\
\hline Danielle A. Becker, MD & $\begin{array}{l}\text { Penn Epilepsy Center, Hospital of } \\
\text { the University of Pennsylvania, } \\
\text { Philadelphia, PA (affiliation at time } \\
\text { work was done) }\end{array}$ & $\begin{array}{l}\text { Interpreted the data; revised the } \\
\text { manuscript for intellectual content; } \\
\text { approved the final version for } \\
\text { submission. }\end{array}$ \\
\hline Lucretia Long, APRN-CNP & $\begin{array}{l}\text { The Ohio State University Medical } \\
\text { Center, Columbus, OH }\end{array}$ & $\begin{array}{l}\text { Interpreted the data; revised the } \\
\text { manuscript for intellectual content; } \\
\text { approved the final version for } \\
\text { submission. }\end{array}$ \\
\hline
\end{tabular}




\begin{tabular}{|c|c|c|}
\hline Nancy Santilli, PNP, MN & $\begin{array}{l}\text { Human Care Systems, Inc., San } \\
\text { Francisco, CA }\end{array}$ & $\begin{array}{l}\text { Interpreted the data; revised the } \\
\text { manuscript for intellectual content; } \\
\text { approved the final version for } \\
\text { submission. }\end{array}$ \\
\hline Lynanne McGuire, $\mathrm{PhD}$ & $\begin{array}{l}\text { MedVal Scientific Information } \\
\text { Services, Princeton, NJ }\end{array}$ & $\begin{array}{l}\text { Wrote initial manuscript draft based } \\
\text { on input from the other authors and } \\
\text { revised the manuscript for } \\
\text { intellectual content under their } \\
\text { guidance. }\end{array}$ \\
\hline Eugenia Y. Peck, PhD & Kantar Health, New York, NY & $\begin{array}{l}\text { Designed the survey; collected the } \\
\text { data; performed the analysis; } \\
\text { interpreted the data; revised the } \\
\text { manuscript for intellectual content; } \\
\text { approved the final version for } \\
\text { submission. }\end{array}$ \\
\hline
\end{tabular}




\section{REFERENCES}

1. Glauser T, Ben-Menachem E, Bourgeois B, et al. ILAE treatment guidelines: evidence-based analysis of antiepileptic drug efficacy and effectiveness as initial monotherapy for epileptic seizures and syndromes. Epilepsia 2006;47:1094-1120.

2. Glauser T, Ben-Menachem E, Bourgeois B, et al. Updated ILAE evidence review of antiepileptic drug efficacy and effectiveness as initial monotherapy for epileptic seizures and syndromes. Epilepsia 2013;54:551-563.

3. Westover MB, Cormier J, Bianchi MT, et al. Revising the "Rule of Three" for inferring seizure freedom. Epilepsia 2012;53:368-376.

4. Chen Z, Brodie MJ, Liew D, Kwan P. Treatment outcomes in patients with newly diagnosed epilepsy treated with established and new antiepileptic drugs: a 30-year longitudinal cohort study. JAMA Neurol 2018;75:279-286.

5. Tian N, Boring M, Kobau R, Zack MM, Croft JB. Active epilepsy and seizure control in adults - United States, 2013 and 2015. MMWR Morb Mortal Wkly Rep 2018;67:437-442.

6. Vingerhoets G. Cognitive effects of seizures. Seizure 2006;15:221-226.

7. Villanueva V, Giron JM, Martin J, et al. Quality of life and economic impact of refractory epilepsy in Spain: the ESPERA study. Neurologia 2013;28:195-204.

8. Josephson CB, Patten SB, Bulloch A, et al. The impact of seizures on epilepsy outcomes: a national, community-based survey. Epilepsia 2017;58:764-771.

9. Thurman DJ, Logroscino G, Beghi E, et al. The burden of premature mortality of epilepsy in high-income countries: a systematic review from the Mortality Task Force of the International League Against Epilepsy. Epilepsia 2017;58:17-26.

10. Mlinar S, Petek D, Cotič Ž, Mencin Čeplak M, Zaletel M. Persons with epilepsy: between social inclusion and marginalisation. Behav Neurol 2016;2016:2018509. 
11. Perucca P, Scheffer IE, Kiley M. The management of epilepsy in children and adults. Med J Aust 2018;208:226-233.

12. Golyala A, Kwan P. Drug development for refractory epilepsy: the past 25 years and beyond. Seizure 2017;44:147-156.

13. Toledo M, Beale R, Evans JS, et al. Long-term retention rates for antiepileptic drugs: a review of long-term extension studies and comparison with brivaracetam. Epilepsy Res 2017;138:53-61.

14. Perucca P, Gilliam FG. Adverse effects of antiepileptic drugs. Lancet Neurol 2012;11:792802.

15. Micoulaud-Franchi JA, Bartolomei F, Duncan R, McGonigal A. Evaluating quality of life in epilepsy: The role of screening for adverse drug effects, depression, and anxiety. Epilepsy Behav 2017;75:18-24.

16. Giussani G, Enia G, Bianchi E, Mecarelli O, Beghi E. The management of epilepsy in clinical practice: Do the needs manifested by the patients correspond to the priorities of the caring physicians? Findings from the EPINEEDS Study. Epilepsy Behav 2020;102:106641.

17. Enia G, Giussani G, Bianchi E, Mecarelli O, Beghi E. The management of epilepsy in clinical practice: Do the timing and severity of the disease influence the priorities of patients and the caring physicians? Data from the EPINEEDS study. Epilepsy Behav 2020:107201 [Epub ahead of print].

18. Benbadis SR, Engel J. The next level of care in epilepsy. Neurol Clin Pract 2019;9:284-285.

19. Martinez-Juarez IE, Funes B, Moreno-Castellanos JC, et al. A comparison of waiting times for assessment and epilepsy surgery between a Canadian and a Mexican referral center. Epilepsia open 2017;2:453-458.

20. Engel J Jr. What can we do for people with drug-resistant epilepsy? The 2016 Wartenberg Lecture. Neurology 2016;87:2483-2489. 
21. Mumford V, Rapport F, Shih P, et al. Promoting faster pathways to surgery: a clinical audit of patients with refractory epilepsy. BMC Neurol 2019;19:29.

22. Fountain NB, Van Ness PC, Bennett A, et al. Quality improvement in neurology: Epilepsy Update Quality Measurement Set. Neurology 2015;84:1483-1487. 
FIGURE LEGENDS

Figure 1 Reasons patients and caregivers did not report all seizures to HCPs

Total $\mathrm{n}$ (patients+caregivers) $=151$. HCPs, healthcare professionals.

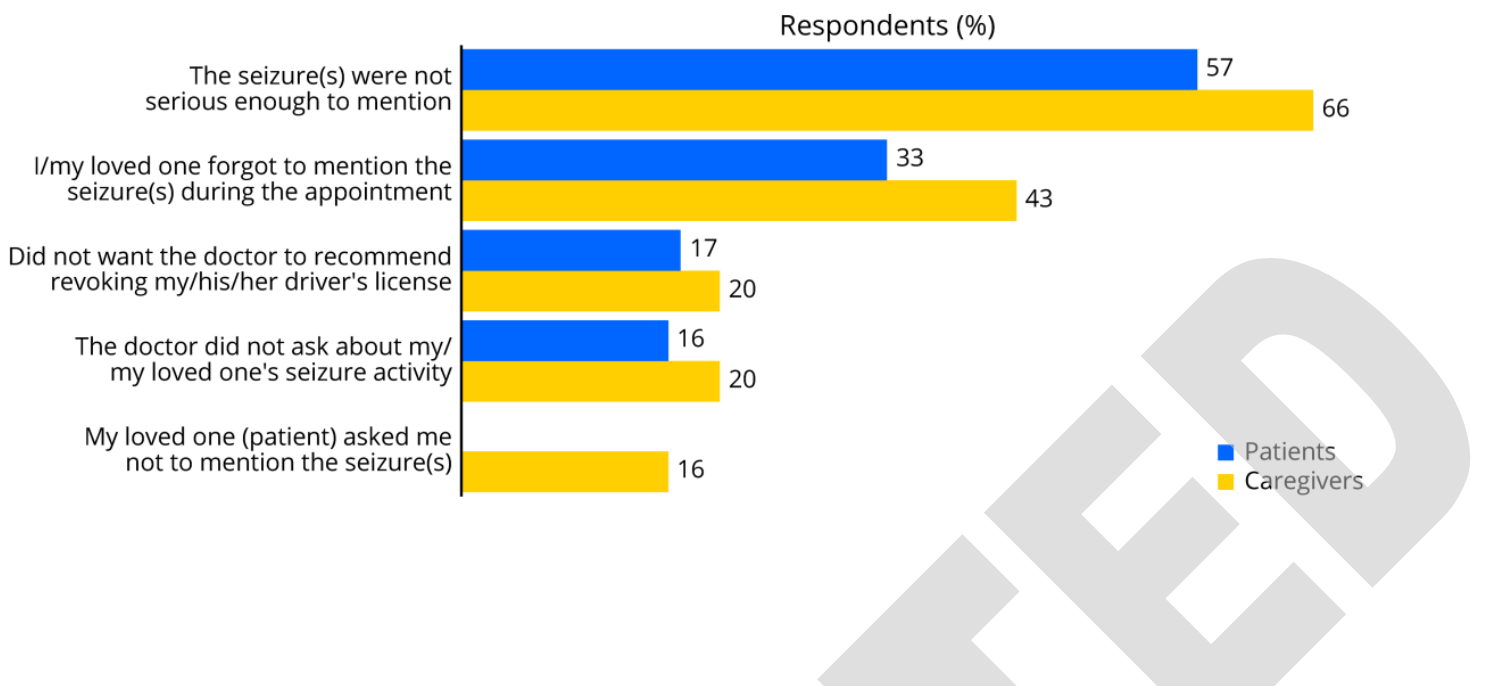

Figure 2 Likelihood of asking HCPs about treatment changes in the next 12 months

HCPs, healthcare professionals.

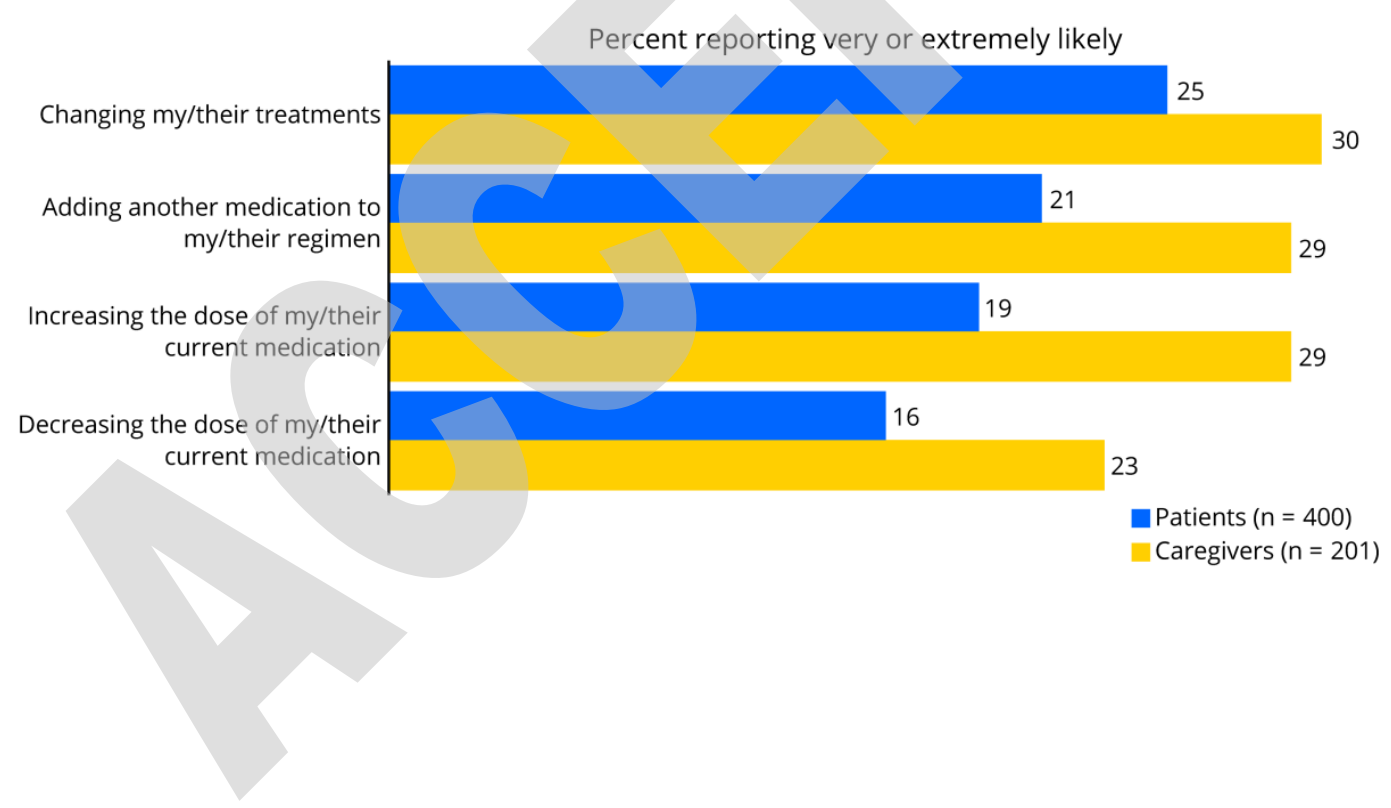


Figure 3 Discussion of surgeries for epilepsy among HCPs, patients, and caregivers ${ }^{\mathrm{a}} p<0.05$ vs patients. ${ }^{\mathrm{b}} p<0.05$ vs caregivers. HCPs, healthcare professionals; NA, not applicable; RNS, responsive neurostimulation.

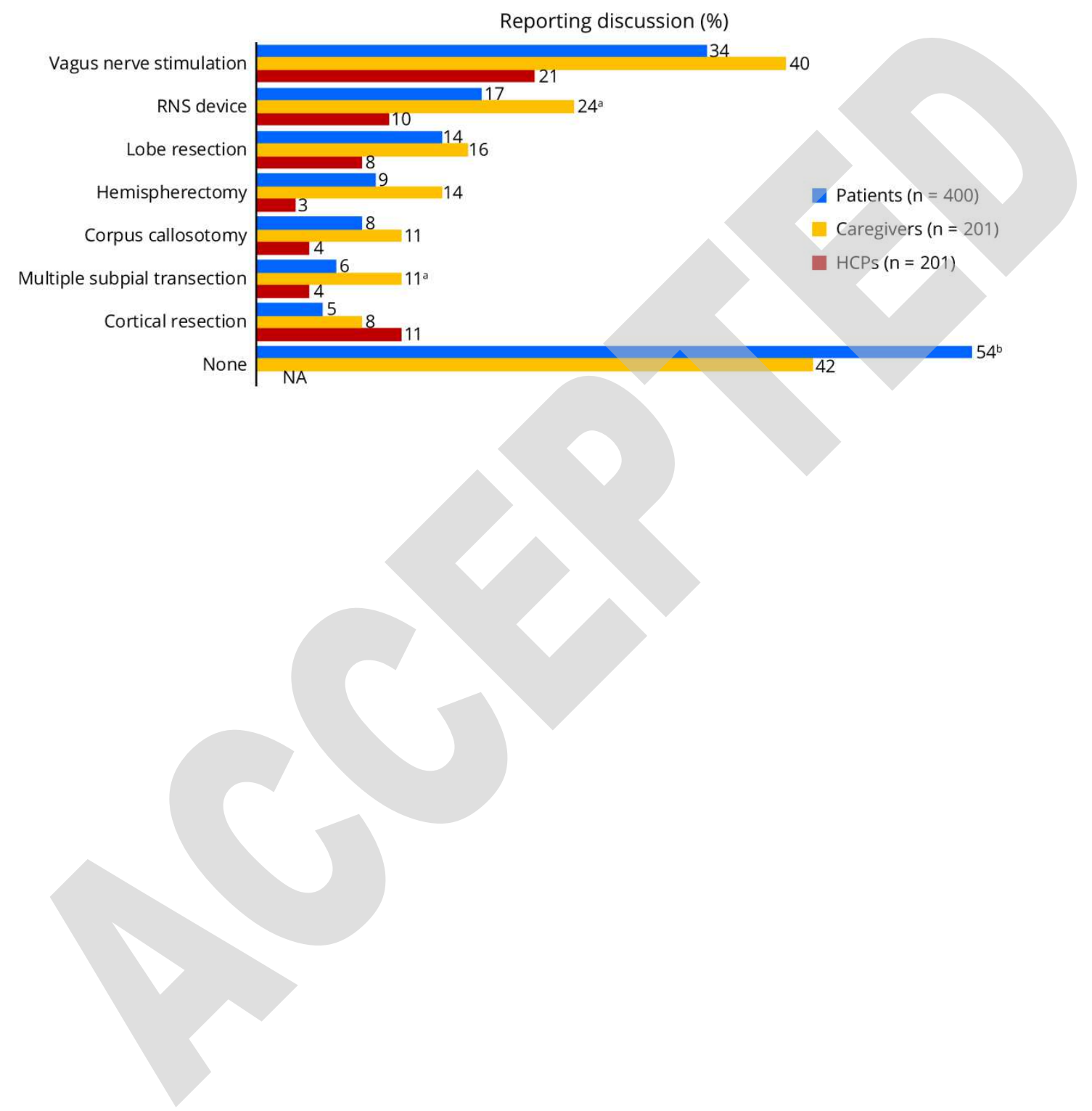


Figure 4 Patient, caregiver, and HCP perspectives on a patient treatment map telling them to see an epileptologist/specialist as soon as they have symptoms

HCPs, healthcare professionals.

Survey question: How important is it that the following program be implemented in the future: a patient treatment map that tells patients and caregivers to see an epileptologists/specialist as soon as they have symptoms, not wait for a long time. Percentages are the sum of respondents who selected the rating on a 5-point Likert scale ranging from $1=$ not at all important to $5=$ extremely important.

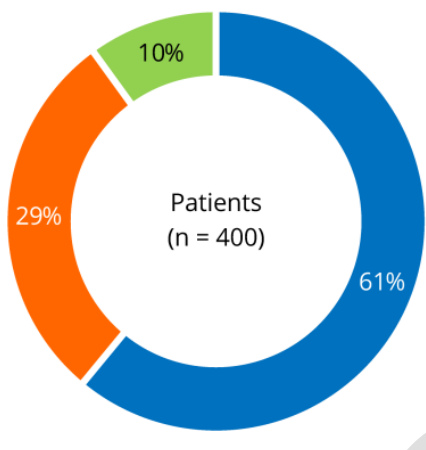

Very/extremely important

Somewhat important

Not very/not at all important
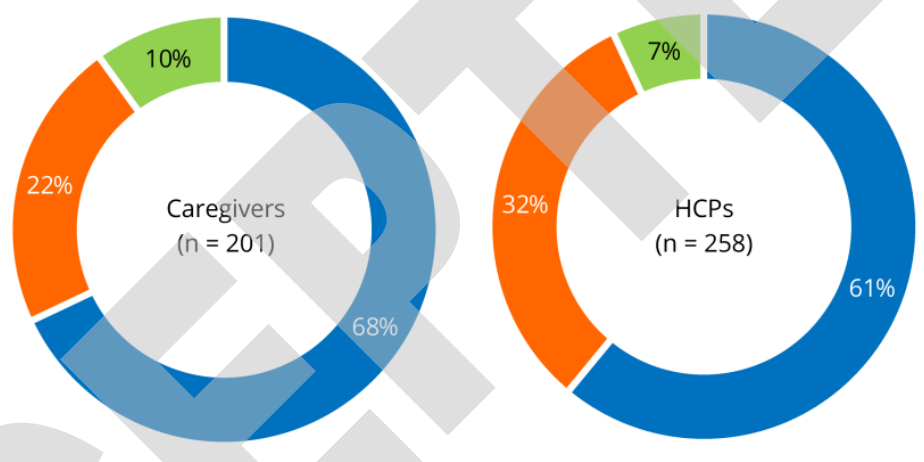

Figure 5 Patients and caregivers report of fear of having a seizure in diverse situations

Percentages are the sum of respondents who reported very or extremely afraid on a 5-point Likert scale ranging from $1=$ not at all afraid to $5=$ extremely afraid.

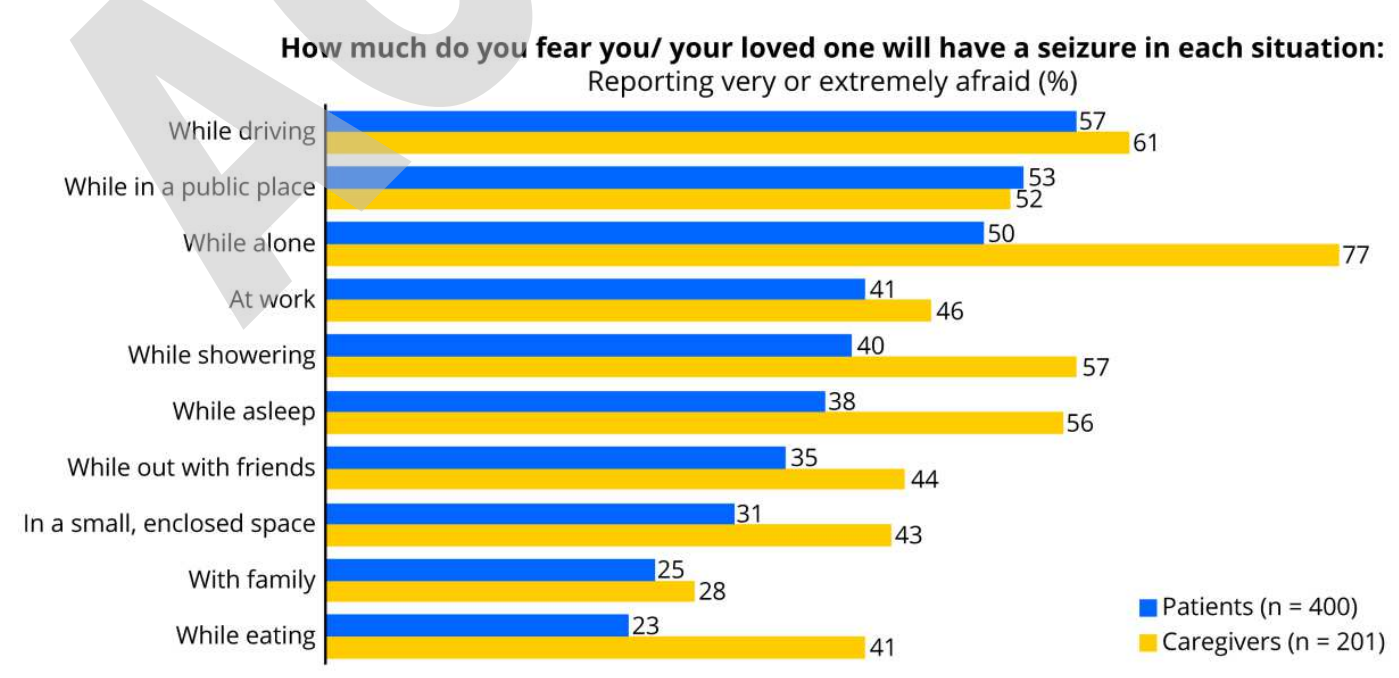

Copyright (C 2021 The Author(s). Published by Wolters Kluwer Health, Inc. on behalf of the American Academy of Neurology. 


\section{Neurology ${ }^{\circ}$ Clinical Practice}

\section{Epilepsy Treatment Complacency in Patients, Caregivers, and Healthcare Professionals}

Patricia E. Penovich, John M. Stern, Danielle A. Becker, et al.

Neurol Clin Pract published online March 9, 2021

DOI 10.1212/CPJ.0000000000001066

This information is current as of March 9, 2021

Updated Information \& Services

Subspecialty Collections

Permissions \& Licensing

Reprints including high resolution figures, can be found at:

http://cp.neurology.org/content/early/2021/03/09/CPJ.0000000000001066.f ull.html

This article, along with others on similar topics, appears in the following collection(s):

All Epilepsy/Seizures

http://cp.neurology.org//cgi/collection/all_epilepsy_seizures

Antiepileptic drugs

http://cp.neurology.org//cgi/collection/antiepileptic_drugs

Epilepsy surgery

http://cp.neurology.org//cgi/collection/epilepsy_surgery_

Information about reproducing this article in parts (figures, tables) or in its entirety can be found online at:

http://cp.neurology.org/misc/about.xhtml\#permissions

Information about ordering reprints can be found online:

http://cp.neurology.org/misc/addir.xhtml\#reprintsus

Neurol Clin Pract is an official journal of the American Academy of Neurology. Published continuously since 2011, it is now a bimonthly with 6 issues per year. Copyright Copyright $@ 2021$ The Author(s). Published by Wolters Kluwer Health, Inc. on behalf of the American Academy of Neurology.. All rights reserved. Print ISSN: 2163-0402. Online ISSN: 2163-0933.

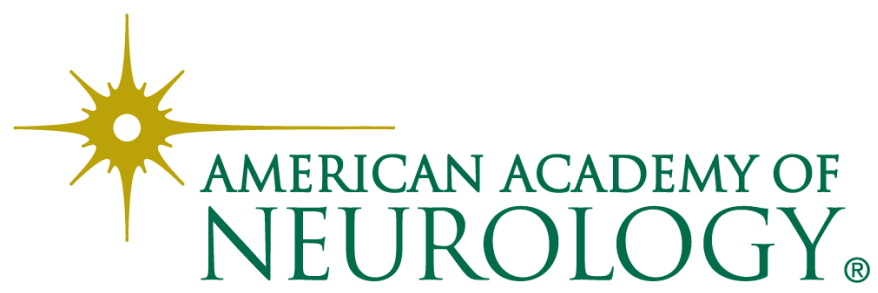

